\title{
Intentional Penetrating Craniocerebral Injury Caused by a Nail: Clinical Presentation and Management of Three Cases
}

\author{
Olatoundji Holden Fatigba ${ }^{*}$ (1) , Luphin Hodé2 ${ }^{\circledR}$, Christian Padonou1 ${ }^{(1)}$ \\ ${ }^{1}$ Unit of Neurosurgery, Faculty of Medicine of Parakou University, Parakou, Benin \\ ${ }^{2}$ Unit of Neurosurgery, Teaching Hospital of Hubert Koutoukou Maga, Cotonou, Benin \\ Email: ^holfatigba@gmail.com
}

How to cite this paper: Fatigba, O.H., Hodé, L. and Padonou, C. (2020) Intentional Penetrating Craniocerebral Injury Caused by a Nail: Clinical Presentation and Management of Three Cases. Open Journal of Modern Neurosurgery, 10, 458-463. https://doi.org/10.4236/ojmn.2020.104046

Received: September 14, 2020

Accepted: October 17, 2020

Published: October 20, 2020

Copyright $\odot 2020$ by author(s) and Scientific Research Publishing Inc. This work is licensed under the Creative Commons Attribution International License (CC BY 4.0).

http://creativecommons.org/licenses/by/4.0/

\begin{abstract}
The authors report on their experience in the medical and surgical management of three cases of penetrating craniocerebral injuries caused by a nail. In all three cases, it was an aggression. Two of the three patients were male. The cranial locations affected were respectively left parietal, right temporal and right frontal. The Glasgow coma score (GCS) was between 9 and 13. None of the patients had a motor deficit. A plain skull radiographs was performed for each patient. All patients underwent surgery and all received antibiotic therapy and tetanus vaccination. In two cases, post-operative outcome was simple. Recovery was complete without sequelae. The patient with a GCS of 9 died the day after surgery.
\end{abstract}

\section{Keywords}

Penetrating Injury, Craniocerebral Injury, Nail

\section{Introduction}

Penetrating craniocerebral injuries are a particular type of traumatic brain injury [1] [2]. Circumstances of occurrence are diverse. Some of them appear spectacular, such as nail wounds [3] [4] [5]. Whatever the unintentional or intentional mode of occurrence, these penetrating cranioencephalic injuries are a therapeutic challenge. The outcome after treatment is unpredictable [6] [7] [8] [9]. The outcome depends on several factors as the point of penetration and trajectory of the nail, intracerebral vascular lesions, bilateral prenchymal involvement and the association of extracerebral lesions. The authors report three cases of intentional penetrating cranioencephalic injuries caused by a nail. 


\section{Observations}

\subsection{Case 1}

A 70-year-old patient was admitted to the emergency room due to for somnolence and ideatory slowing down. She has no prior psychiatric history. Following accusations of witchcraft, she was allegedly assaulted by neighbors who drove a nail into her head. The nail was located in the left parietal region (Figure 1(a)). The examination found no other signs of physical abuse or associated injuries. The patient was calm, drowsy and had a Glasgow coma score (GCS) of 13. In the impossibility of performing a brain CT-scan, a plain skull radiographs, with face and profile incidence, was performed. A nail was objectified, with an oblique trajectory from outside to inside, going from the left parietal lobe to the middle of the base of the skull (Figure 1(b)). The distal tip of the nail was at the limit of the median line of the brain without crossing it (Figure 1(c)).

\subsection{Case 2}

It was a 30 year old patient without a profession. He was found with patient $\mathrm{N}^{\circ} 3$ in a farm after he was reported missing for 48 hours. On admission to the hospital, the patient was agitated and had a fever. He was apparently aggressed by people from his community who accused him of larceny. His temperature was $39^{\circ} \mathrm{C}$ associated with tachycardia. His GCS was 9 but he had no focal motor desability. The presence of a nail firmly planted in the right temporal region was observed (Figure 2(a)). There was no deformation of the cranial vault. The patient had no focal deficits. There was no sigma of other physical abuse. Due to lack of financial assistance, a plain skull radiographs was performed. This radiograph revealed a filiform, rectilinear, horizontal nail with a straight, horizontal trajectory from outside to inside with a straight temporal starting point (Figure 2(b)) and passing over the midline of the brain (Figure 2(c)). Surgical extraction of the nail combined with antibiotic therapy had been performed. Despite this immediate management of the patient, he died the following day. This patient

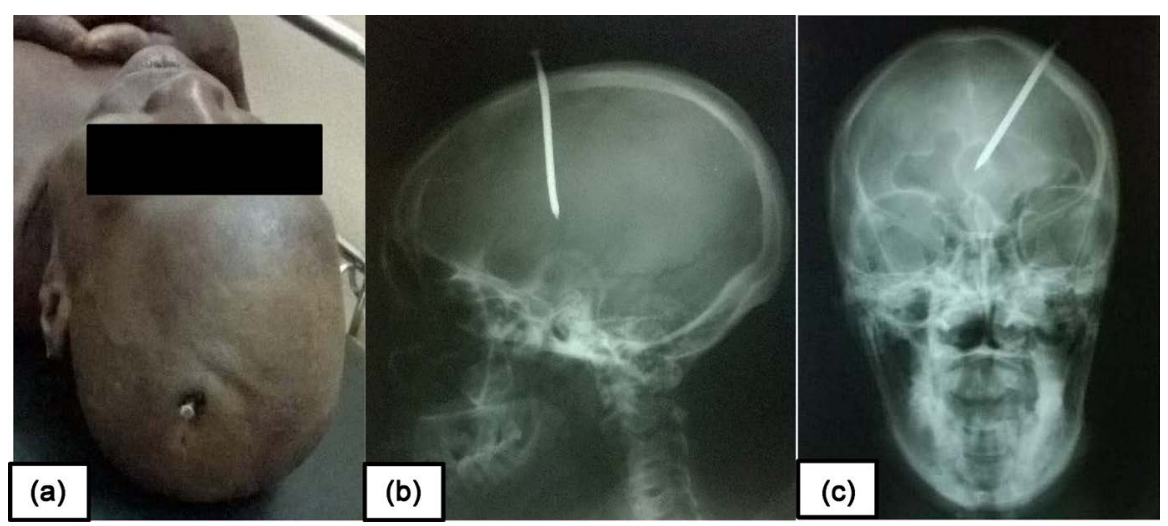

Figure 1. Macroscopic view of a penetrating craniocerebral injury caused by a nail, whose point of penetration is visible in the left parietal region (a). The radiograph shows a trajectory towards the middle stage of skull base (b). The nail remained in the left cerebral hemisphere (c). 
had worsening fever, respiratory distress followed by heart failure.

\subsection{Case 3}

The patient was 31 years old and had no occupation. He was found on a farm after he was reported missing for two days. On admission to hospital, the patient was conscious. He was allegedly assaulted by people in his community who accused him of larceny. He had a Glasgow coma scale (GCS) of 13. He complained of headaches and pain. A nail was observed stuck in the right frontal hump (Figure 3(a)). There was no deformation of the cranial vault. The patient had no focal deficit. There was no stigma of other physical abuse. Because there was no financial assistance available, he has benefited from a plain skull radiographs. This X-ray revealed a thread-like nail with an oblique trajectory from outside to inside from the right frontal region to the midline of the base of the skull (Figure 3(b)) and not exceeding the midline of the brain (Figure 3(c)).

These three patients were undergoing surgery on the same day of admission. In all three cases the surgical technique was the same: A circumferential craniotomy with a diameter of approximately $1.5 \mathrm{~cm}$ was performed around the nail after exposure of the entry point (Figure 4(a)). The nail was then removed in a single step without any manoeuvre allowing viewing of the cerebral wound

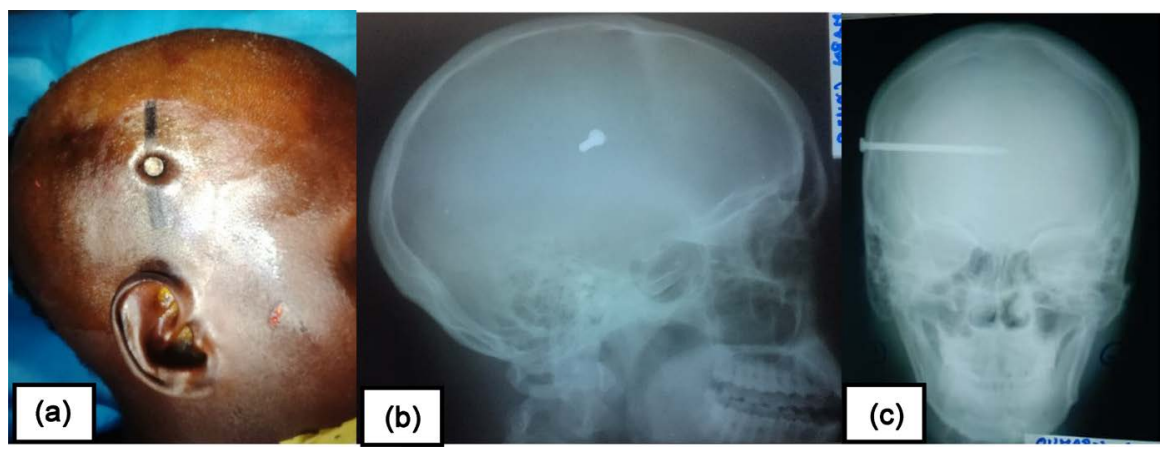

Figure 2. Macroscopic view of a penetrating craniocerebral injury caused by a nail, whose point of penetration is visible in the right temporal region (a). The radiograph shows a temporal entry point (b) and a rectilinear, horizontal trajectory and a crossing of the midline (c).

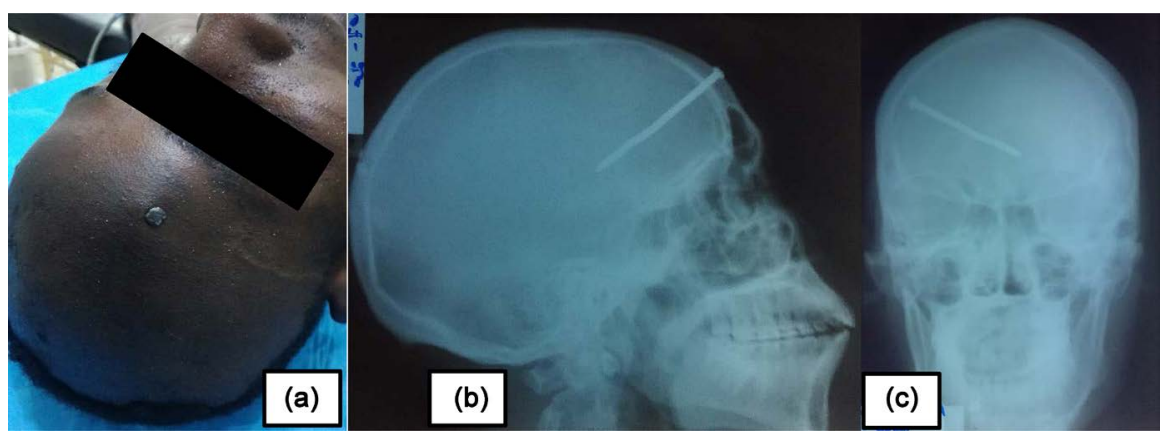

Figure 3. Macroscopic view of a penetrating wound caused by a nail whose point of penetration is visible in the right frontal region (a). The radiograph shows a frontal entry point and a rectilinear, oblique trajectory at the mid-stage of the skull base ((b), (c)). 


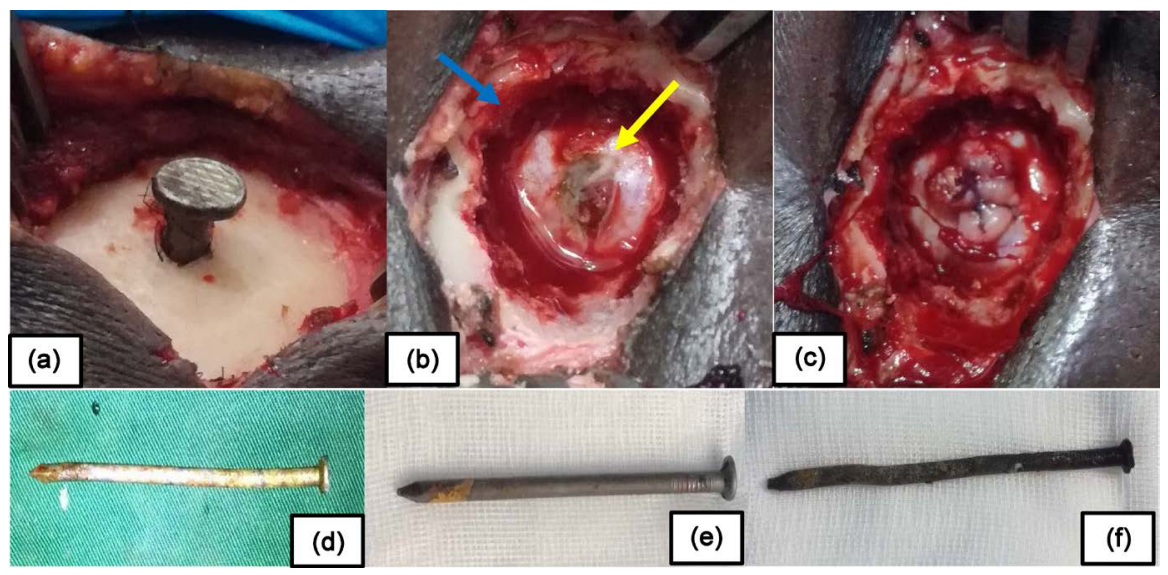

Figure 4. (a) Exposure of the nail penetration point; (b) craniotomy (blue arrow) and exposure of the brain wound (yellow arrow); (c) suture of the dura mater strengthened with a patch. Macroscopic view of the nails after extraction (d), case 1; (e), case 2 and (f), case 3.

(Figure 4(b)). After irrigation of the wound with physiological saline, the dura mater entrance point was closed by suture using non-absorbable suture. This suture was reinforced with a strengthening epicranial patch (Figure 4(c)).

All of these patients were treated with a combinaison of ceftriaxone, metronidazole and tetanus vaccination was administterd. Exploration of the extracted nails did not detect the presence of toxic substance (Figures 4(d)-(f)). Postoperative management was simple for patients 1 and 3. No sequelae were observed. Patient No. 2, despite antibiotic medication, died the following day of surgery.

\section{Discussion}

Penetrating craniocerebral injury is not frequent. However, series of one to four cases have been reported by different authors [3] [9] [10] [11]. The circumstances in which they occur often appear to be accidental or reported in patients with psychiatric conditions [4] [5] [12] [13]. In psychiatric cases, the use of a nail gun has been described [4] [5] [12] [13]. More than one cranial nail is observed in these cases. As reported in a limited number of cases [14], the three cases described in our series were due to a popular vindictive desire or a will to take justice into one's own hands. For a particular accusation (theft, witchcraft), the victims found themselves surrendered to the population. These are injuries that are both preventable and appealing to everyone's citizenship. These circumstances of occurrence have obliged us to inform the police, who in turn, as required by law, have opened a criminal investigation.

Clinical presentations can be different depending on the circumstances of occurrence, location, number of nails, involvement of one or both cerebral hemispheres and associated intra- and extracerebral lesions. In the three reported cases, no associated hemorrhagic syndrome was found. The entrance hole appeared to be non-degrading and punctiform in all three cases. Two of the three patients 
had a GCS greater than 12 .

The skull X-ray was the only imaging used on our three patients. These patients did not have the opportunity to perform any other explorations. However, CT scan was the exploration most strongly reported by several authors [5] [8] [14] [15]. It has the advantage of highlighting the nail's trajectory from its entry hole to the distal tip and the structures affected by the crossing. Brain CT-scan thus offers a good understanding of the lesions caused by the nail. Fear of vascular damage has led to the recommendation of cerebral angiography [9] [11] [15]. The absence of these explorations in the three cases described did not affect our strategy of surgical and medical management of the nail.

Our treatment was immediate and identical to that reported by other authors [7] [8] [11]. Antibiotic therapy, vaccination, craniotomy, careful extraction of the nail, lavage of the wound and suture closure of the wound. All of our patients had a single intracranial nail and all were unilateral, compared with other authors who reported multiple uni or bilateral cases. Of the three cases described, two patients recovered and had no sequelae. In these two cases, the localizations appeared innocuous, the lesion was unilateral (mono hemispherical) and the GCS was greater than 12. The absence of intracranial hypertension or associated extracerebral lesions appears to contribute to the good prognosis of these penetrating craniocerebral injuries [4] [8] [14]. These factors are in opposition to those of the deceased patient. The localization was temporal, the trajectory was straight, the midline was crossed creating a bihemispheric wound, and the patient on admission had signs such as fever and agitation. These factors can be considered as pejorative.

The absence of evidence of vascular injury raises doubts about the contribution of such an injury to the death of this patient. In the absence of vascular injury and with appropriate management of nail-penetrating craniocerebral injury, patients with a penetrating craniocerebral injury survive or have few sequelae [3] [6] [8] [10].

\section{Conclusion}

Penetrating craniocerebral injuries caused by a nail are a therapeutic challenge. They are preventable depending on the circumstances in which they occurred. The treatment is medical and surgical. The vital and functional prognosis appears to be good but can be affected depending on the patient's condition on admission and the associated damage factors.

\section{Conflicts of Interest}

The authors declare no conflicts of interest regarding the publication of this paper.

\section{References}

[1] Rosenwasser, R.H., Andrews, D.W. and Jimenez, D.F. (1991) Penetrating Cranioce- 
rebral Trauma. Surgical Clinics of North America, 71, 305-316. https://doi.org/10.1016/S0039-6109(16)45381-8

[2] Fatigba, O.H. and Lawin, B.L. (2013) Spontaneous Migration of Intracranial Bullet: Clinical Pattern and Management. African Journal of Neurological Sciences, 32, 61-64.

[3] Chen, P.C., Tsai, S.H., Chen, Y.L. and Liao, W.I. (2014) Post-Traumatic Cerebral Infarction Following Low-Energy Penetrating Craniocerebral Injury Caused by a Nail. Journal of Korean Neurosurgical Society, 55, 293-295.

https://doi.org/10.3340/jkns.2014.55.5.293

[4] Luo, W., Liu, H., Hao, S., Zhang, Y., Li, J. and Liu, B. (2012) Penetrating Brain Injury Caused by Nail Guns: Two Case Reports and a Review of the Literature. Brain Injury, 26, 1756-1762. https://doi.org/10.3109/02699052.2012.700085

[5] Alain, J., Lavergne, P., St-onge, M., D’astous, M. and Cote, S. (2017) Bilateral Nail Gun Traumatic Brain Injury Presents as Intentional Overdose: A Case Report. Canadian Journal of Emergency Medicine, 20, 1-4.

[6] Makoshi, Z., AlKherayf, F., Da Silva, V. and Lesiuk, H. (2016) Nail Gun Injuries to the Head with Minimal Neurological Consequences: A Case Series. Journal of Medical Case Reports, 10, 58. https://doi.org/10.1186/s13256-016-0839-1

[7] Jeon, Y.H., Kim, D.M., Kim, S.H. and Kim, S.W. (2014) Serious Penetrating Craniocerebral Injury Caused by a Nail Gun. Journal of Korean Neurosurgical Society, 56, 537-539. https://doi.org/10.3340/jkns.2014.56.6.537

[8] Wu, R., Ye, Y., Liu, C., Yang, C. and Qin, H. (2018) Management of Penetrating Brain Injury Caused by a Nail Gun: Three Case Reports and Literature Review. World Neurosurgery, 112, 143-147. https://doi.org/10.1016/j.wneu.2018.01.127

[9] Awori, J., Wilkinson, D.A., Gemmete, J.J., Thompson, B.G., Chaudhary, N. and Pandey, A.S. (2017) Penetrating Head Injury by a Nail Gun: Case Report, Review of the Literature, and Management Considerations. Journal of Stroke and Cerebrovascular Diseases, 26, e143-e149. https://doi.org/10.1016/j.jstrokecerebrovasdis.2017.04.004

[10] Kaufman, H.H., Schwab, K. and Salazar, A.M. (1991) A National Survey of Neurosurgical Care for Penetrating Head Injury. Surgical Neurology, 36, 370-377. https://doi.org/10.1016/0090-3019(91)90026-6

[11] Sedney, C.L., Harshbarger, T., John Orphanos, J. and Collins, J.J. (2012) Penetrating Injury to the Superior Sagittal Sinus by a Nail in a 4-Year-Old Child: A Case Report. Pediatric Emergency Care, 28, 1220-1223. https://doi.org/10.1097/PEC.0b013e318271ff3b

[12] Selvanathan, S., Goldschlager, T., McMillen, J. and Campbell, S. (2007) Penetrating Craniocerebral Injuries from Nail-Gun Use. Journal of Clinical Neuroscience, 14, 678-683. https://doi.org/10.1016/j.jocn.2006.02.017

[13] Min, S.H., Kweon, C.Y. and Shin, W. (2017) Penetrating Brain Injury Caused by a Nail Gun. The Nerve, 3, 81-84. https://doi.org/10.21129/nerve.2017.3.2.81

[14] Diallo, M., Sogoba, Y. and Kanikomo, D. (2019) An Unusual Case of Penetrating Head Injury by Nails. AJNS, 38, 60-69.

[15] Carrillo-Ruiz, J.D., Juarez-Montemayor, V., Mendez-Viveros, A., Frade-Garcia, A. and Bolanos-Jimenez, R. (2013) Skull Stab Wound from a Metal Rail Road Nail Perforating the Right Frontal Lobe. Brain Injury, 27, 973-977.

https://doi.org/10.3109/02699052.2013.794959 